l'occasion de déployer son activité, ce qu'elle ferait sans être protégée par la Convention de Genève. Mais il était temps (de l'avis général des sous-comités) que la Croix-Rouge italienne se mît en mesure d’assister au besoin nos blessés et nos malades dans la colonie de l'Erythrée, et de leur apporter, avec son emblème, le salut de la civilisation et de la charité universelle. »)

\title{
LE COMMANDEUR EMILIO SERNY ${ }^{1}$
}

Le $1^{\text {er }}$ juin 1894 mourait à Rome un homme dont toute la vie avait élé consacrẻe à des œuvres philanthropiques : le commandeur Emilio Serny. Il s'intéressail à toutes les œuvres humanitaires, et, à peine l'idée de fonder, à Rome, un Comité de la Croix-Rouge avaitelle été émise en 1879, qu'il l'adopta avec son ardeur habituelle; dès la constitution de ce Comité central, le 8 juin 1879, il fut appelé à en faire partie. Il devint, en 1887, secrétaire du Conseil de direction, et dans la suite secrétaire général de l'Association. Lors de la réunion à Rome de la cinquième conférence internationale de la Croix-Rouge, il se fit remarquer par son activité et par son zèle, et plusieurs souverains étrangers lui prodiguèrent les marques de leur admiration. Il y dépensa si bien ses forcesqu'il fut atteint, les travaux étant à peine terminés, de la maladie qui devait l'enlever dans le courant de l'année dernière, à l'âge de 54 ans, au milieu des regrets unanimes de tous ceux qui avaient appris à connaitre son infatigable dévouement.

\section{JAPON}

\section{GUERRE SINO-JAPONAISE}

Dans notre précédent Bulletin (p 13), nous avions cru pouvoir attribuer à la Croix-Rouge anglaise l'envoi, auprès de l'armée chinoise, d'un personnel sanitaire dont la mission avait échoué,

\footnotetext{
1 D'après le Bulletin italien, no 11.
} 